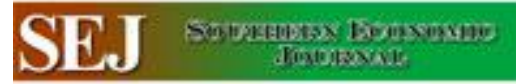

\title{
Foreign Direct Investment and Inflation
}

\section{Author(s): Selin Sayek}

Source: Southern Economic Journal, Vol. 76, No. 2 (Oct., 2009), pp. 419-443

Published by: Southern Economic Association

Stable URL: http://www.jstor.org/stable/27751474

Accessed: 16-10-2017 13:40 UTC

JSTOR is a not-for-profit service that helps scholars, researchers, and students discover, use, and build upon a wide range of content in a trusted digital archive. We use information technology and tools to increase productivity and facilitate new forms of scholarship. For more information about JSTOR, please contact support@jstor.org.

Your use of the JSTOR archive indicates your acceptance of the Terms \& Conditions of Use, available at http://about.jstor.org/terms 


\title{
Foreign Direct Investment and Inflation
}

\author{
Selin Sayek*
}

\begin{abstract}
Multinational enterprises (MNEs) are able to shift investments between home and host countries to minimize the negative effects of changes in the macroeconomic environment. This article formalizes a model that allows studying this investment-smoothing behavior of MNEs facing inflation taxes in both the home and the host country. The MNE is allowed to invest in two economies, home and host, and to finance its foreign direct investment (FDI) either through domestic or foreign sources. The investment smoothing by the MNE is studied for cases of both vertical and horizontal FDI. The results suggest FDI is used as a hedging tool, mitigating the effects of inflation taxes even if there are no formal hedging mechanisms. The investment-smoothing reaction of MNEs depends on the reason for investment, the financing sources of FDI, and the substitutability between factors of production. Finally, this investmentsmoothing possibility (FDI) reduces the real negative effects of inflation.
\end{abstract}

JEL Classification: E31, F21, F23

\section{Introduction}

In recent years interest in understanding the determinants of foreign direct investment (FDI) has intensified hand in hand with an increasing volume of FDI flows. From 1990 to 2005 , the total worldwide FDI inflows increased from $\$ 203$ billion to $\$ 974$ billion. Almost all developing countries are competing to attract a major share of these inflows. In fact, the share of net FDI inflows in the gross domestic product (GDP) of middle income countries has risen from $0.74 \%$ in the 1970 s to $1.08 \%$ between 1985 and 1994 , and to $2.85 \%$ between 1995 and 2005.' The intensified competition to attract more FDI has led to changes in the regulatory frameworks provided by almost all countries. According to the recent World Investment Report (UNCTAD 2003), during the period 1991-2002, around 95\% of the changes in worldwide laws governing FDI have been favorable to multinational firm activity. Establishment of investment promotion agencies as well as provision of fiscal incentives have accompanied these improvements in local regulatory environments. Given the objectives of host countries to attract high-quality investments and to ensure benefits

* Department of Economics, Bilkent University. Bilkent Ankara 06800. Turkey: E-mail sayek@bilkent.edu.tr.

I am very grateful to my advisor. Kent Kimbrough, for his support and help. without which this research wouldn't have been possible. I would also like to thank Robert Conrad, Enrique Mendoza. Ed Tower, and Dennis Yang for their guidance and helpful comments. I have also received valuable comments from Duke University Macroeconomics Workshop participants and Royal Economic Society 2001 Conference participants, as well as the two referees. All errors remain mine.

Received April 2004: accepted March 2008.

'Data is obtained from the World Bank. World Development Indicators (2006). The middle income classification follows the World Bank's definition. 
from such foreign activity, it is important to fully understand the factors influencing the FDI flows.

This article primarily studies the role of inflation among the factors that drive FDI. Inflation rates have increased from around 5 to $10 \%$ on average in developing countries during the 1970 s, followed by an increase of $49 \%$ on average among developing countries between 1985 and 1994. This trend of increasing inflation rates has been reversed in the late 1990s; the inflation rates in developing countries have on average declined to $9.2 \%$ during 1995-2004, a period during which the net FDI inflows as a share of GDP have more than doubled in the middle income countries. Given the focus among developing countries to attract more FDI, it is interesting to analyze whether the increasing inflation rates in the 1970s and 1980s might have been a deterrent for FDI inflows and whether their reversal in the 1990s might have contributed to the increase in FDI inflows to these economies. Despite not providing conclusive evidence, the coincidences of high inflation and low FDI versus the low inflation and high FDI inflows into these developing countries motivates investigation of the possible links between the two variables.

Therefore the broad objective of this framework is to study the effects of inflation on the investment decision of multinational enterprises (MNEs). Changes in inflation rates of the domestic or foreign country are anticipated to alter the net returns and optimal investment decisions of the MNE. In studying the explicit role of inflation in determining the investment pattern of MNEs across domestic and foreign locations, I use a model that is in fact discussing an investment-smoothing behavior of the MNE that faces domestic and foreign nominal shocks. In this framework the act of investment smoothing captures a shift of investments across locations and not across time. My argument is in line with Aizenman (1992), who notes that the goal of diversifying exposure to country-specific shocks induces producers to become multinationals. This investment-smoothing behavior can further be thought of as a production flexibility approach, where the MNE can shift production (and trade decisions) depending on the relative favorability of conditions in the two countries as discussed in Sung and Lapan (2000). Parallel to these two papers, the current model shows that the existence of FDI opportunities is tantamount to increased hedging possibilities against inflation taxes even if no explicit hedging instrument is modeled. In fact, MNEs minimize the negative effects of policy changes, in this case expected changes in the inflation rate, via a shift in the location of production across home and host countries. The model shows that the ability of a multinational to invest in two alternative economies does reduce the real effects of nominal shocks.

There are models in the literature that have studied the investment decisions of MNEs in general equilibrium models with monetary shocks. However, a majority of these studies have focused on the exchange rate shocks, not inflation shocks as I do in this article. Three such articles are Aizenman (1992), Devereux and Engel (1999), and Russ (2007), which all focus on the effects of exchange rate-related policies on FDI decisions. Aizenman (1992) models the production flexibility approach into an option value model to discuss the role of exchange rate uncertainty in FDI decisions, finding that volatility under flexible exchange rates can in fact deter FDI. Devereux and Engel (1999), on the other hand, show that if the MNEs are serving the host market, then exchange rate volatility can be loosely associated with higher MNE activity. Both models are relevant to the current study, not in their focus on the link between exchange rate uncertainty and FDI, but in their simultaneous incorporation of MNE activity and monetary phenomena in the 
same model. ${ }^{2}$ Furthermore, these papers tend to discuss the effects of these shocks on foreign investment decisions without considering the investment-smoothing effects made possible by the tandem decision of domestic and foreign investment by the MNE. The current model considers the effects of inflation on the domestic and foreign investment alternatives simultaneously, incorporating the fact that the FDI decision is not independent of the domestic investment decision of the firm. As such, the article contributes to the literature that studies the relationship between monetary processes and FDI without explicitly controlling for the possibility of investment smoothing by the MNE.

Besides, although there are models in the literature that incorporate MNEs into general equilibrium models with money, the differential role of domestic inflation and foreign inflation on vertical and horizontal FDI have not been discussed explicitly in any of these models. The current analysis incorporates monetary phenomena into the model, with a focus on the links with both vertical and horizontal FDI. As such, my model is similar in spirit to Aizenman and Marion (2004), who discuss the association between several uncertainties and vertical as well as horizontal FDI. Their results emphasize that uncertainty's effect is larger on vertical FDI than on horizontal FDI. The current study's results echo this by finding that the investment smoothing of MNEs, upon changes in monetary processes' of the home and host countries, differs between vertical and horizontal FDI. This is an important finding, pointing to the importance of differentiating across initial motives of FDI in modeling MNE behavior and studying the determinants of FDI.

Another important characteristic of the model is that it allows for the financing of the FDI activity to occur through both domestic and foreign sources. Several studies in the literature have provided evidence that MNEs not only use finances from the home country sources but that they also use foreign country financing. For example, Feldstein (1994) shows that, with the goal of minimizing the tax burden, U.S. foreign affiliates raise a significant amount of financial resources in their host country markets. This access to host country financial markets is furthermore a means of hedging against fluctuations in future local currency earnings. This is a point further emphasized by Lehmann, Sayek, and Kang (2004), who find that there is an association between the extent of exposure to local currency revenues and contribution of host country finances to total financing, generating a relationship between FDI and the financial market development of the host country. Taking a cue from these studies, my model allows for financing from both domestic (home) country sources and foreign (host) country sources, where not only does FDI become a hedging instrument, but a shift between alternative means

\footnotetext{
2 One could argue that the current model allows for an alternative means of discussing the link between the exchange rate and FDI. The role of exchange rates as a possible cause of MNE activity attracted attention following the synchronous depreciation of the U.S. dollar in the 1980s with the United States becoming a host country for MNEs. Explaining the mechanism behind this link, Froot and Stein (1991), assuming imperfections in the capital markets, and Blonigen (1997), assuming imperfections in the goods market, formalized the wealth effects of exchange rate movements that alter the FDI behavior of firms. Prior to analyzing the links between exchange rates and FDI using imperfect markets, several studies had simply tested the importance of changes in the level of exchange rates on the investment decisions of multinationals with no consideration of the mechanisms behind this link. Despite the recent efforts of analyzing the mechanism, there is no agreement on how exchange rates and FDI are related. This article suggests an additional possible explanation, where inflation rates and exchange rates are related through the effects of the monetary process on both variables. Therefore, the observed relationship between exchange rates and FDI might in fact be due to the effects of inflation on the foreign firm's investment decisions.
} 
of financing also does. ${ }^{3}$ Allowing for differential financing sources to the MNE in a framework of investment smoothing is one of the novelties of this article.

In summary, the current analysis of investment-smoothing behavior is done in a comprehensive way to allow not only for the characteristic of the FDI to differ (being vertical or horizontal) but also its financing composition (between domestic and foreign resources) to be a choice variable of the MNE. This is, to the best of my knowledge, the first model to formalize the role of inflation and how the investment smoothing made possible by FDI reduces the real effects of the inflation tax. The main finding of my article is that firms benefit from having the opportunity to invest abroad and the ability to finance their foreign investment activity through different financial markets. In other words, the option of diversifying the investment decision across countries and across financing means reduces the negative effect of inflation on physical investment fluctuations. The MNE could mitigate the loss in net benefit caused by higher domestic (foreign) inflation by increasing foreign source-financed FDI (domestic investment) and limiting the response of domestic (foreign) investment to the inflation tax. A detailed analysis suggests that the extent of reduction in the FDI financed through alternative financial markets depends on the motivation for FDI. In the case of vertical FDI, results show that both the quantitative and qualitative effects of a higher domestic inflation tax on the domestically financed portion of FDI depends on the substitutability of the factors of production. The lower the degree of substitutability between the factors of production, the higher the possibility that domestically financed FDI also decreases in response to domestic inflation. Finally, the results suggest that the response of the composition of the financing of FDI also heavily depends on the degree of substitutability of the factors of production, specifically for the case of vertical FDI. The empirical implications of the model's findings are detailed in the following sections.

The rest of the article is organized as follows: An overview of the basic pillars of the model is discussed in section 2, followed by the setup for the vertical FDI case, where the optimization problem for the representative agent is discussed in detail in section 3. In section 4 the same issue is discussed under conditions that are conducive for the MNE to carry out horizontal FDI. The two cases are compared in section 5, and section 6 concludes.

\section{Basic Pillars of the Model}

This article builds a model that formalizes the effects of inflation on FDI, an open question that remains unanswered as of yet. The real effects of inflation are captured by introducing money through cash-in-advance constraints as in Lucas (1982). In this framework, home country inflation acts as a tax on labor supply and domestic investment, while host country inflation acts as a tax on FDI, via a mechanism similar to Stockman (1981) and

\footnotetext{
${ }^{3}$ Because the model does not explicitly include financial intermediaries, the different sources of financing of the FDI will be thought of as the real (or physical) goods necessary to carry out the investment. This means that the hedging activity implications of the model will be in cases where there are no formal financial markets to allow for financial hedging instruments. Furthermore, the lack of financial intermediaries in the model also implies that in both cases of vertical and horizontal FDI there will be no funds available for borrowing; rather. the financing will be differentiated by the source of the physical good converted into investment goods. While this can be viewed as a limitation, it does allow for simplifying the model and studying the investment-smoothing activities of the firms: hence, it can be viewed as a starting point.
} 
Aschauer and Greenwood (1983), where the earnings from use of resources are available a period later, during which inflation erodes the real value of these nominal values. In the broadest sense the model shows that domestic and foreign inflation affect both domestic and foreign investment. Increased domestic (foreign) inflation rate increases foreign (domestic) investment via changes in the intertemporal consumption pattern of the agent. Inflation causes an increase in current consumption, which reflects the opportunity cost of investments. Domestic inflation increases domestic consumption, reducing the cost of FDI. Similarly, an increase in foreign inflation reduces the cost of domestic investment, shifting investments from the foreign economy to the domestic economy. This mechanism shows that the firms shift their investment as a response to changes in inflation as a means of investment smoothing.

In a recent paper, Russ (2007), modeling heterogeneity across firms, constructs a model that takes into account the endogeneity of exchange rates and multinational firm activity. The model is relevant for the current investigation in that it emphasizes the impact of monetary policy on the multinational firm's investment decision; while the current analysis focuses on the effects of inflationary processes, Russ's (2007) work focuses on the effects of exchange rate uncertainty. As such the analyses can be viewed as being complementary portions of the analysis of the effects of monetary phenomena on investment decisions of MNEs. The current article introduces time lags in the investment-decision process of MNEs via cash-in-advance (CIA) constraints, while sunk costs and nominal rigidities drive the results in Russ (2007).

Although the article's results emphasize the necessity of differentiating across the initial driving forces of FDI (i.e., the motivation of the MNE), the current model takes this decision as given and studies the subsequent investment decision of MNEs that are either defined as vertical or horizontal in the nature of their foreign investment. In other words, rather than discussing the decision of initial investment and mode of entry choice of the MNE, the model will study the behavior of subsequent investment for alternative "reasons of investment" in the host country. In the broadest sense, the nature of FDI can be classified as horizontal or vertical. As discussed in Navaretti and Venables (2004), the level of trade costs determines whether the equilibrium will render horizontal or vertical FDI. When trade costs (which they have for both the intermediate goods, components, and the final goods, through trade costs on assembly) are very low, the equilibrium renders vertical FDI (VFDI). This is in fact a fragmented production structure, which would lead to vertical specialization or disintegration of production. ${ }^{4}$ Helpman (1984) introduces VFDI into a Heckscher-Ohlin trade model where the overseas operations of the MNE is modeled as a separate stage of production and allows the creation of a third tradable good and an additional trading opportunity. This theoretical framework points to the complementarity of trade and FDI, suggesting that MNEs that carry out VFDI are driven by cost differences, where the costs mainly include factor costs.

Horizontal FDI (HFDI) occurs when the same product is produced in two different locations (countries) by the MNE. Markusen and Venables $(1998,2000)$ construct models that incorporate the features of the new trade theory, incorporating imperfect market structures in the models and showing the ranges of parameters where multinational firms operate. The model suggests that measures of market size - in this case defined as the differences in country size and in relative endowments by the authors-and the level of costs related to trade,

\footnotetext{
${ }^{4}$ See Feenstra (1998) and Hummels, Ishii, and Yi (2001) for a detailed discussion of vertical specialization and disintegration of production phenomena, respectively. The discussion of VFDI is provided in Chapter 4 of Navaretti and Venables (2004), while a discussion of HFDI is provided in Chapter 3 of the same book.
} 
transportation, and investment are the major determinants of the extent of MNE activities, where the former group of variables bear more importance for HFDI.

In the broadest sense firms choose to invest in foreign economies either to serve the foreign market directly or to exploit the cost advantages of producing in different locations, making the former horizontal and the latter VFDI in nature. I also refer to the terminology by Dunning (1993) regarding the incentives to carry out foreign investment, including (i) market-seeking, (ii) efficiency-seeking, and (iii) resource-seeking foreign investments. In the following discussion the market-seeking FDI is used interchangeably with HFDI, while efficiency- and resourceseeking FDI are used interchangeably with VFDI.

In both the VFDI and HFDI modeling of the MNE activities, I will have a representative agent maximizing expected lifetime utility, which depends on consumption of a final good and leisure. The model will assume that the household is both a consumer and a producer. While the utility depictions will be parallel across the two cases, the production functions and the use of FDI will be different. These will become clear in the following sections where both cases are detailed.

Finally, it is worth noting that because I am interested in the choice of the MNE, I will model this from the perspective of the MNE's home country, where the MNE will be choosing how much to invest in the domestic economy and the foreign economy. As such the model is more of a "FDI outflows model" than "determinants of FDI inflows." In the following section, the issue is analyzed for the case of VFDI, where the MNE is assumed to face no trade or transportation costs and to invest in a foreign country for the purpose of fragmenting production and seeking resources or efficiency improvements. In section 4 the MNE is assumed to face trade costs, instigating HFDI, where the MNE produces a similar good in different locations to serve the foreign market.

\section{Vertical FDI}

VFDI is based on the premise that trade costs are low enough to not completely offset the foreign comparative advantage in the goods produced in the host country and that there are enough wage differences in the two countries that it makes sense to fragment production. This could also reflect itself as the existence of outsourcing rather than greenfield investments by the MNE. In this framework, however, I assume that the MNE owns an intangible asset, and to avoid possible technical spillovers it takes capital to the foreign country and produces the "intermediate" good itself. ${ }^{5}$

The production structure is as follows. There is a final consumable good, $X$, which is produced in the home country. The production of $X$ requires domestic labor $L^{d}$, domestic capital $K^{d}$, and the foreign-produced intermediate goods, $Z$. It is assumed that because of technological differences the marginal productivity of labor is much lower in a foreign country.

\footnotetext{
${ }^{5}$ The early work on FDI focused on comparative advantage and differences in capital costs [see Dunning (1993), chapter 4]. In the 1960s the analysis of multinational firm activity was evolving around the organizational structure of the firm in answering the question of determinants of FDI. Vernon (1966), Kindleberger (1969), and Hymer (1976) developed an approach based on the industrial organization literature and argued that FDI occurs not because of differences in cost of capital but because certain assets are worth more under foreign control. These assets are what are labeled as intangible assets.
} 
This lower productivity allows for sufficient cost differences between the countries to render fragmented production possible. ${ }^{6}$ The intermediate good produced in the foreign country by the MNE is exported back to the home country and is not consumed as a final product but is only used as an intermediate product in the production of $X$. This is based on the premise that trade and transportation costs are low, which at the first stage lead to the VFDI. For simplicity I assume no trade distortions or transportation costs, which allows the discussion of VFDI.

The MNE takes some capital from the home country to the foreign country (i.e., the host country). This is part of the FDI. However, it also raises capital in the foreign country. ${ }^{7}$ Therefore the total FDI includes both the capital injected from the home country $\left(K^{x}\right)$ and capital raised from the foreign country $\left(K^{z}\right)$. Here I make the assumption that the capital injected from the home country is in fact the good $X$ and the capital used from the foreign country is good $Z$. Thinking of FDI being represented as similar in characteristics to physical goods allows for an alternative means of differentiating this type of investment from portfolio investment. The model will also include adjustment costs, discussed later in detail, for all three types of capital (i.e., domestic, domestically financed FDI, and foreign source-financed FDI), where such frictions further differentiate portfolio and direct investments.

The production of the intermediate good $Z$ is carried out in the foreign country by the MNE. In fact this is the result of the VFDI. The production of $Z$ uses foreign capital, which includes both the home country and the source country financed foreign capital, $K^{x}$ and $K^{z}$, respectively. One can envisage that the total amount of accumulated FDI is composed of $K^{x}$, denoting the part financed from domestic sources, and $K^{z}$, denoting the part financed from foreign sources. ${ }^{8}$

The consumers in the home country maximize utility. ${ }^{9}$ The preferences of the individuals are given by the expected utility function, maximizing utility over their consumption of the final good and their leisure time:

$$
\sum_{t=0}^{\infty} \beta^{t} U\left(c_{t}^{x},\left(1-l_{t}^{s}\right)\right)
$$

where $c_{t}^{x}$ is the consumption of good $X$ at time $t, l_{t}^{s}$ is the labor supplied, and the time endowment is normalized to 1 unit.

The law of motions for the three types of capital are as follows, where for simplicity I assume that the depreciation rate $\delta$ is the same across the three capital types. The law of motion for the domestic capital is

$$
K_{t+1}=K_{t}(1-\delta)+I_{t}
$$

\footnotetext{
${ }^{6}$ As noted in the preceding discussion, this article does not endogenously discuss the decision of whether to do FDI, but it rather studies the response of FDI to changes in the macroeconomic environment in the home or the host country.

${ }^{7}$ This follows, as previously discussed, Feldstein (1994) and Lehmann. Sayek, and Kang (2004).

${ }^{8}$ While the use of final produced goods as investment goods across separate production locations does cause some discrepancy between the modeled FDI and the actual FDI realized in the data, the model is a starting point in analyzing the role of real activities in providing hedging possibilities for multinationals and adds value to the discussions in the literature. The same limitations, yet value added, would apply to the VFDI case. A more realistic model would require final goods being explicitly modeled as consumption and investment goods. For simplicity I refrain from doing so and note that the current model allows discussing the use of physical investments as a hedging instrument and is a starting point.

${ }^{9}$ I don't model the host country utility maximization because I am interested in the behavior of the MNE that originates in the home country. As such this is a partial equilibrium analysis.
} 
The law of motion for the domestic-financed foreign capital is

$$
K_{t+1}^{x}=K_{t}^{x}(1-\delta)+I_{t}^{x},
$$

while the law of motion for the foreign sourced foreign capital is as follows:

$$
K_{t+1}^{z}=K_{t}^{z}(1-\delta)+I_{t}^{z} .
$$

There are four assets in the economy available to the home consumer: domestic government bonds $(b)$, foreign government bonds $\left(b^{*}\right)$, nominal domestic currency holdings $(M)$, and nominal foreign currency holdings $(N)$.

Money serves two purposes in this model. Following Lucas (1982), it is assumed that money is necessary to carry out transactions, and it imposes a liquidity constraint on the individual. An individual arrives at the beginning of period $t$ with money left over from period $t$ -1 , denoted by $m_{t-1}$ for domestic money holdings and $n_{t-1}$ for foreign money holdings. At the start of period $t$, the individual settles all debt contracts from the last period, sells and buys new debt, and trades currencies. The cash acquired in the asset market is used to purchase consumption and investment goods in the product market, which operated upon the closing of the market. ${ }^{10}$ Adding the investment good to the stock of capital, the producer produces the final good next period, $t+1$. The profits from the sale of goods produced will be used for transactions in the asset market in the following period, $t+2 .^{11}$

To differentiate between physical and financial assets, I assume that there are adjustment costs incurred when installing capital. As Mendoza (1991) has shown, these costs are necessary in dynamic open economy models to avoid unrealistically large swings in investment rates. Additionally, as noted previously, introduction of adjustment costs allows the model to capture FDI rather than portfolio investments. These costs are modeled as goods that have to be purchased to install the capital; therefore, they appear in the CIA constraints. As investment goods, the goods purchased for capital installment are assumed to be purchased using the currency of the corresponding country of origin of the capital to the purchase of the capital good itself.

The adjustment costs for the domestic and foreign capital, respectively, are $(\phi / 2)\left(K_{t+1}-K_{t}\right)^{2}$ for domestic investment, $(\phi / 2)\left(K_{t+1}^{x}-K_{t}^{x}\right)^{2}$ for the domestically financed FDI, and $(\phi / 2)\left(K_{i+1}^{z}-K_{t}^{z}\right)^{2}$ for the foreign source-financed FDI. The functional form choice of the adjustment costs follows Mendoza (1991), where the cost of changing the capital stock by fixed amounts increases with the speed of adjustment. This creates an incentive for gradual investment changes by the agents.

All transactions are assumed to be carried out in the seller's currency. I introduce money into the model using CIA constraints. Domestic currency is used to purchase domestically produced consumption goods $\left(c^{v}\right)$, domestic investment goods $(I)$, and domestically financed

\footnotetext{
${ }^{10}$ Both the domestic investment and part of the foreign investment good is purchased in the home country, while the remainder of the foreign investment good is purchased in the host country.

"The appropriateness of CIA modeling can be proven with a comparison of interest on checking accounts and alternative investments. In countries with high inflation levels and macroeconomic instability, these spreads are usually significant enough to allow for modeling the optimal behavior of representative agents in a CIA framework. See Kimbrough (1990) and Gokcekus and Tower (1997) for further discussion of the CIA models and the appropriateness of such modeling techniques, respectively.
} 
foreign capital goods $\left(I^{r}\right)$. According to the described timing structure, denoting domestic currency as $M$, the CIA constraint for the domestic currency becomes the following:

$$
M_{t} \geq P_{t}^{r}\left[c_{t}^{y}+K_{t+1}-K_{t}(1-\delta)+K_{t+1}^{x}-K_{t}^{y}(1-\delta)+\frac{\phi}{2}\left(K_{t+1}-K_{l}\right)^{2}+\frac{\phi}{2}\left(K_{t+1}^{x}-K_{l}^{y}\right)^{2}\right] .
$$

Similarly the CIA constraint for the foreign currency shows the use of foreign currency. Foreign currency, $N$, is used to purchase the foreign intermediate good, $Z$, and the foreignfinanced FDI, $I^{\prime}$, including its adjustment cost. Denoting foreign currency as $N$, the CIA constraint for the foreign currency becomes the following:

$$
N_{t} \geq P_{i}^{* *}\left[Z_{l}+K_{l+1}^{z}-K_{l}^{z}(1-\delta)+\frac{\phi}{2}\left(K_{l+1}^{z}-K_{l}^{z}\right)^{2}\right] .
$$

The representative agent can hold domestic or foreign bonds, $b$ and $b^{*}$, respectively. The returns on the bond holdings are denoted as $R$ and $R^{*}$, respectively. The exchange rate is denoted as the price of the foreign currency in terms of the domestic currency and is represented by $e$. The proceeds from sales in the host country or from transactions in the foreign asset market are converted into the domestic currency at the bilateral nominal exchange rate, $e$. The overall budget constraint for the consumer then becomes the following:

$$
\begin{aligned}
& b_{t-1}\left(1+R_{t-1}\right)+e_{t} b_{t-1}^{*}\left(1+R_{t-1}^{*}\right)+\left[P_{t-1}^{v} f\left(K_{t-1}, l_{t-1}^{d}, Z_{t-1}\right)-w_{t-1} l_{t-1}^{d}\right]+w_{t-1} l_{t-1}^{s} \\
& \quad+e_{t-1}\left[P_{t-1}^{* *} g\left(K_{t-1}^{*}, l_{t-1}^{l^{*}}, K_{t-1}^{z}\right)-w_{t-1}^{*} l_{t-1}^{l *}\right]+m_{t}+e_{t} n_{t}+T R_{t} \geq M_{t}+e_{t} N_{t}+b_{t}^{h}+e_{t} b_{t}^{f},
\end{aligned}
$$

where $T R_{t}$ denotes the transfers to the household from the government in period $t$. The money growth processes are as follows:

$$
M_{t+1}=\mu_{t+1} M_{t}
$$

for the domestic currency, where $\mu$ is the gross growth rate of the domestic money supply, and

$$
N_{t+1}=\mu_{t+1}^{*} N_{t},
$$

for the foreign currency, where $\mu^{*}$ is the gross growth rate of the foreign money supply.

To ensure stationarity, I divide all the nominal values by their respective monetary values. The normalized variables are denoted as $\hat{P}_{t}^{*}=P_{i}^{*} / M_{t}, \hat{P}_{t}^{*-}=P_{t}^{*-} / N_{1}, \hat{b}_{t}=b_{t} / M_{1}, \hat{b}_{1}^{*}=b_{t}^{*} / N_{t}, \hat{w}_{t}$ $=w_{t} / M_{t}, \hat{w}_{t}^{*}=w_{t}^{*} / N_{t}$, and $\hat{e}_{t}=\mathcal{C}_{t} N_{t} / M_{t}$. For simplicity I will drop the use of the circumflex; all variables in the following analysis are transformed to ensure stationarity.

Each agent's choices are conditional upon their own past actions and information about the aggregate economy. The aggregate state of the economy at the beginning of time $t$ is described by the beginning of period domestic capital stock $K$ : the beginning of period FDI capital stocks, both domestically financed, $K^{x}$, and foreign source-financed, $K^{*}$; the current period realizations of money growth rates. $\mu$ and $\mu^{*}$ : the stochastic processes governing the evolution of these growth rates; and the time profiles for interest rates and relative prices.

Following Lucas (1982), the nominal interest rates in both currencies are always assumed to be positive. Because this implies the opportunity cost of holding money is positive, there will be no benefit to holding excess cash. Therefore, the CIA constraints hold with equality at all times, reflecting that no money is held between periods and that the purchases of goods and bonds are restricted by the resources of the agent, i.e., the interest earned on bond holdings and profits from production and wage earnings. ${ }^{2}$ This feature is used to obtain the following 
budget constraint, Equation 11. The solution to the individual problem will be found from the following value function:

$$
V\left(K, K^{x}, K^{z}, b, b^{*}, \sigma\right)=\max U\left(c_{t}^{x}, 1-l_{t}^{s}\right)+E\left[\beta V\left(K^{\prime}, K^{\prime x}, K^{\prime z}, b^{\prime}, b^{\prime *}, \sigma^{\prime} \mid \sigma\right)\right],
$$

where $E$ denotes the expectation operator, $V$ is the value function, and $\sigma$ denotes the aggregate state vector; values with a prime are the value of the variables one period ahead, subject to the following:

$$
\begin{aligned}
& \frac{b_{t-1}^{h}}{\mu_{t}}\left(1+R_{t-1}\right)+\frac{e_{t} b_{t-1}^{f}}{\mu_{t}^{*}}\left(1+R_{t-1}^{*}\right)+\left[\frac{P_{t-1}^{x}}{\mu_{t}} f\left(K_{t-1}, l_{t-1}^{d}, Z_{t-1}\right)-\frac{w_{t-1} l_{t-1}^{d}}{\mu_{t}}\right]+\frac{w_{t-1}}{\mu_{t}} l_{t-1}^{s} \\
& +e_{t-1}\left[\frac{P_{t-1}^{z *}}{\mu_{t}^{*}} g\left(K_{t-1}^{x}, l_{t-1}^{d *}, K_{t-1}^{z}\right)-\frac{w_{t-1}^{*}}{\mu_{t}^{*}} l_{t-1}^{d *}\right]+T R_{t} \\
& \geq P_{t}^{x}\left(c_{t}^{x}+K_{t+1}-K_{t}(1-\delta)+\frac{\phi}{2}\left(K_{t+1}-K_{t}\right)^{2}+K_{t+1}^{x}-K_{t}^{x}(1-\delta)+\frac{\phi}{2}\left(K_{t+1}^{x}-K_{t}^{x}\right)^{2}\right) \\
& \quad+e_{t} P_{t}^{z *}\left(Z_{t}+K_{t+1}^{z}-K_{t}^{z}(1-\delta)+\frac{\phi}{2}\left(K_{t+1}^{z}-K_{t}^{z}\right)^{2}\right)+b_{t}^{h}+e_{t} b_{t}^{f},
\end{aligned}
$$

and the stochastic process governing the exogenous variables.

The control vector for the individual will be $x_{t}=\left(c_{t}^{x}, l_{t}^{d}, l_{t}^{s}, l_{t}^{d *}, Z_{t}, K_{t+1}, K_{t+1}^{x}, K_{t+1}^{z}\right.$, $\left.b_{t}^{h}, b_{t}^{f}\right)$ to maximize the expected lifetime utility such that the transformed budget constraint holds.

Before discussing the optimization results that follow, I define the equilibrium for this model as a set of initial conditions, stochastic processes for the exogenous variables, choices for endogenous variables from the first-order conditions defined later in the individual's problem. In equilibrium, the prices of goods and assets are functions of the current state of the economy; the pricing functions are such that the CIA constraints hold with equality; all markets clear; government's budget constraint holds with equality; and given the pricing functions, the stochastic processes of the exogenous variables and the initial conditions, and the individual's choices will solve the constrained maximization defined previously.

\section{First-Order Conditions}

The first-order conditions (FOC) for this economy provide insights regarding the optimal decisions of the individuals and the equilibrium in the economy. The FOCs for each of these variables are as follows:

$$
\begin{gathered}
U_{c \times t}-\lambda_{t} P_{t}^{r}=0, \\
\lambda_{t}=\beta\left(1+R_{t}\right) E_{t}\left(\frac{\lambda_{t+1}}{\mu_{t+1}}\right),
\end{gathered}
$$

\footnotetext{
12 In a model with different timing of transactions and information, Svensson (1985) shows that CIA constraints need not always hold with equality. The schedule of timing creates precautionary demand for money in his model, where money holdings vary inversely with nominal interest rates; whereas, in the Lucas timing used earlier, money holdings do not change with nominal interest rates.
} 


$$
\begin{gathered}
\lambda_{t} e_{t}=\beta\left(1+R_{t}^{*}\right) E_{t}\left(\frac{\lambda_{t+1}}{\mu_{t+1}^{*}} e_{t+}\right), \\
\beta E\left(\frac{P_{t}^{x} \lambda_{t+1}}{\mu_{t+1}} f_{l_{t}}-\frac{w_{t} \lambda_{t+1}}{\mu_{t+1}}\right)=0, \\
-U_{l_{t}^{s}}=\beta w_{t} E_{t}\left(\frac{\lambda_{t+1}}{\mu_{t+1}}\right), \\
\beta E\left[e_{t+1} \frac{\lambda_{t+1}}{\mu_{t+1}^{*}}\left(P_{t}^{z_{t}^{*}} g_{l_{t}^{*}}-w_{t}^{*}\right)\right]=0, \\
\beta E_{t}\left(\frac{P_{t}^{x} \lambda_{t+1}}{\mu_{t+1}} f z_{t}\right)=P_{t}^{-*} e_{t} \lambda_{t},
\end{gathered}
$$

$$
\begin{aligned}
& \beta^{2} E_{t}\left(\frac{\lambda_{t+2}}{\mu_{t+2}} P_{t+1}^{x} f_{K_{t+1}}\right)+\beta E_{t}\left\{\lambda_{t+1} P_{t+1}^{x}\left[(1-\delta)+\phi\left(K_{t+2}-K_{t+1}\right)\right]\right\} \\
& \quad=\lambda_{t} P_{t}^{x}\left[1+\phi\left(K_{t+1}-K_{t}\right)\right], \\
& \beta^{2} E_{t}\left(\frac{\lambda_{t+2}}{\mu_{t+2}^{*}} e_{t+1} P_{t+1}^{z *} g_{K_{t+1}^{x}}\right)+\beta E_{t}\left\{\lambda_{t+1} P_{t+1}^{x}\left[(1-\delta)+\phi\left(K_{t+2}^{x}-K_{t+1}^{x}\right)\right]\right\} \\
& \quad=\lambda_{t} P_{t}^{x}\left[1+\phi\left(K_{t+1}^{x}-K_{t}^{x}\right)\right], \\
& \beta^{2} E_{t}\left(\frac{\lambda_{t+2}}{\mu_{t+2}^{*}} e_{t+1} P_{t+1}^{z *} g_{K_{t+1}^{z}}\right)+\beta E_{t}\left\{\lambda_{t+1} P_{t+1}^{z *} e_{t+1}\left[(1-\delta)+\phi\left(K_{t+2}^{x}-K_{t+1}^{x}\right)\right]\right\} \\
& \quad=\lambda_{t} P_{t}^{z *} e_{t}\left[1+\phi\left(K_{t+1}^{x}-K_{t}^{x}\right)\right] .
\end{aligned}
$$

Equation 12 is the FOC with respect to the consumption of good $X$; Equation 13 is the FOC with respect to the domestic bond holdings; Equation 14 is the FOC with respect to the foreign bond holdings; Equation 15 is the FOC with respect to the domestic labor demand; Equation 16 is the FOC with respect to the labor supply; Equation 17 is the FOC with respect to the foreign labor demand; Equation 18 is the FOC with respect to the intermediate input $Z$; Equation 19 is the FOC with respect to the domestic capital; Equation 20 is the FOC with respect to the domestically financed foreign capital; and finally, Equation 21 is the FOC with respect to the foreign-financed foreign capital.

From Equation 13 I know that $\lambda_{t}$ and $E_{t}\left(\lambda_{t+1} / \mu_{t+1}\right)$ are nonzero. Using Equations 13 and 15 I am able to write:

$$
P_{t}^{x} f_{l_{t}^{d}}=w_{t} .
$$

Using the conditions for the foreign bond holdings together with that for the foreign labor demand, I am able to write the foreign wage rate as follows (using Equations 14 and 17):

$$
P_{t}^{z^{*}} g_{l_{t}^{d^{*}}}=w_{t}^{*} .
$$


Equations 22 and 23 show that both the domestic and foreign labor used in production are paid according to their marginal productivity. ${ }^{13}$

Using Equations 12, 13, and 16, I obtain the following:

$$
-\frac{U_{l_{l}}}{U_{c \times l t}}=\frac{f_{l t}}{\left(1+R_{t}\right)}
$$

which shows the marginal rate of substitution between leisure and consumption. This equation shows one channel of the real effects of inflation. The agent provides its labor services in period $t$, producing extra output in period $t$ by its marginal productivity $f_{i t}$ and increasing the nominal value of production. Earnings from this production are only available to purchase cash in the period $t+1$ asset market because the earnings are collected after the asset market in period $t$ is closed. Therefore, the real value of these nominal earnings will be eroded by inflation during period $t$. The amount of borrowing that can be done today will be at most the present value of future earnings, which is the real earnings in period $t+1$ discounted to period t. This describes the right side of Equation 24, which also reflects the marginal rate of transformation between labor and consumption. The left side of the equation reflects the marginal rate of substitution between labor and consumption, reflected via the marginal utilities of each. The nominal interest rate rises with inflation, increasing the inflation tax on labor, effectively at the rate $R_{t} /\left(1+R_{t}\right)$. This is a standard feature of CIA models with laborleisure choice.

According to Equation 24, at the optimum, the marginal disutility of an additional unit of labor must be equal to the present value of the expected increased consumption due to the wage earned. From Equation 22 I can also state that the marginal product of labor must equal the real wage.

From the host country's perspective, there is a similar wedge between the marginal rate of substitution of labor for consumption and the marginal productivity of labor, created by the CIA constraint. From the home country's perspective, though, Equation 23 shows that, at the optimum, the marginal productivity of foreign labor is equal to its real return (wages).

Using Equations 12, 13, and 18, I obtain the following expression, which reflects the optimal decision for the quantity of intermediate input that will be used $(Z)$.

$$
\frac{P_{i}^{Y} U_{C, Y t}}{\left(1+R_{t}\right)} f_{z,}=e_{t} P_{t}^{-*} U_{c, Y t}
$$

Equation 25 shows the optimal level of $Z$ that will be purchased. The right side of the equation is the utility that the consumer has to forego in the period it purchases the intermediate good $Z$. The left side, on the other hand, shows the return to the consumer $Z$-i.e., the utility that the additional production of good $X$ allows when the firm purchases one more unit of $Z$. Equation 25 could also be interpreted as capturing the terms-of-trade for the host country, the ratio of the price of the home country's importable good to the price of its exportable good; the interpretation is possible because the equation can be rewritten as follows ${ }^{14}$ :

\footnotetext{
${ }^{13}$ For simplicity I am assuming that the foreign country labor supply to the MNE is perfectly elastic. Although this implies a very different utility function for the host country residents, it is used for simplification purposes and does not alter the qualitative results of the model.

${ }^{14}$ The model assumes a small economy that takes the international prices and the foreign monetary processes as given. Similarly, the domestic monetary process is also taken as given.
} 


$$
\frac{e_{t} P_{t}^{z^{*}}}{P_{t}^{x}}=\frac{f_{z_{1}}}{\left(1+R_{t}\right)} .
$$

The FOCs further provide insight regarding the exchange rate market. Manipulation of Equations 13 and 14 suggests

$$
\frac{\left(1+R_{t}\right)}{\left(1+R_{t}^{*}\right)}=\frac{E_{t}\left(\frac{\lambda_{t+1}}{\lambda_{t}} \frac{1}{\mu_{t+1}}\right)}{E_{t}\left(\frac{\lambda_{t+1}}{\lambda_{t}} \frac{1}{\mu_{t+1}^{*}} \frac{e_{t+1}}{e_{t}}\right)} .
$$

This condition can be interpreted as the interest parity. If the agent had participated in the forward market, then the budget constraint would have the following term on its right side: $\left[\left(s_{t-1} / \mu_{t}\right)-\left(e_{t} / \mu_{t}^{*}\right)\right] A_{t-1}$, where $A_{t-1}$ is the foreign currency sale that is contracted in period $t$ -1 and will be settled in period $t$, and $s_{t}$ is the forward exchange rate.

The FOC on this asset would be as follows:

$$
E_{t}\left(\frac{s_{t} \lambda_{t+1}}{\mu_{t+1}}\right)=E_{t}\left(\frac{e_{t+1} \lambda_{t+1}}{\mu_{t+1}^{*}}\right)
$$

Using this and Equation 27 would imply the following covered interest parity condition:

$$
\frac{s_{t}}{e_{t}}=\frac{\left(1+R_{t}\right)}{\left(1+R_{t}^{*}\right)} .
$$

I next study the FOCs about the domestic and foreign capital. Using Equations 12, 13, and 19 , I obtain the following equation, which equates the present value of the benefits from increasing domestic capital by one unit next period, i.e., investing one more unit this period, to its cost.

$$
\begin{aligned}
& \beta^{2} E_{t}\left(U_{c x_{t+2}} \frac{P_{t+1}^{r}}{P_{t+2}^{x}} \frac{1}{\mu_{t+2}} f_{K_{t+1}}\right)+\beta E_{t}\left\{U_{c x_{t+1}}\left[(1-\delta)+\phi\left(K_{t+2}-K_{t+1}\right)\right]\right\} \\
& \quad=U_{c x_{t}}\left[1+\phi\left(K_{t+1}-K_{t}\right)\right] .
\end{aligned}
$$

The left side of Equation 30 shows the benefit from investing one more unit today domestically. The increased capital stock allows for increased production next period, which allows for increased utility in two periods' time. This is captured in the first term on the left side. The second term of the equation reflects the value to the consumer of the additional consumption this extra capital stock allows next period. One unit of increased investment this period implies that, keeping the future capital stock levels unchanged, the agent has the option of investing less next period and therefore has more resources available for consumption. Because $1-\delta$ of the capital stock remains undepreciated, the incremental value created by the current investment can be used for consumption instead. This extra consumption provides the marginal utility of $U_{c^{\prime} x+1}(1-\delta)$.

The same applies to the domestically financed foreign capital (FDI), where Equation 20 can be rewritten as follows:

$$
\begin{aligned}
& \beta^{2} E_{t}\left(U_{c x_{t+2}} \frac{e_{t+1} P_{t+1}^{* *}}{P_{t+2}^{x}} \frac{1}{\mu_{t+2}^{*}} g_{K_{t+1}^{x}}\right)+\beta E_{t}\left\{U_{c^{x} y+1}\left[(1-\delta)+\phi\left(K_{t+2}^{x}-K_{t+1}^{x}\right)\right]\right\} \\
& \quad=U_{c_{x x}}\left[1+\phi\left(K_{t+1}^{x}-K_{t}^{x}\right)\right] .
\end{aligned}
$$


The left side of the equation captures the benefit from investing one more unit in the foreign country. Investing one more unit today allows for increased capital stock tomorrow, which allows for increased production of the intermediate good $Z$ next period. This increased production allows for increased consumption in period $t+2$, which allows for higher levels of utility.

Looking into the foreign-financed FDI, Equation 21 can be rewritten as follows:

$$
\begin{aligned}
& \beta^{2} E_{t}\left(U_{c x_{t+2}} \frac{e_{t+1} P_{t+1}^{* *}}{P_{t+2}^{x}} \frac{1}{\mu_{t+2}^{*}} g_{K_{t+1}^{z}}\right)+\beta E_{t}\left\{U_{c x_{t+1}} \frac{P_{t+1}^{* *} e_{t+1}}{P_{t+1}^{x}}\left[(1-\delta)+\phi\left(K_{t+2}^{z}-K_{t+1}^{z}\right)\right]\right\} \\
& \quad=U_{c x_{t}} \frac{P_{t}^{z *} e_{t}}{P_{t}^{x}}\left[1+\phi\left(K_{t+1}^{x}-K_{t}^{z}\right)\right] .
\end{aligned}
$$

As previously, the left side of the equation captures the benefit from investing one more unit in the foreign country when this investment is financed in the foreign country via goods produced in the boundaries of the foreign country. Investing one more unit today allows for increased foreign-capital stock tomorrow, which allows for increased production of the intermediate good $Z$ next period. This increased production allows for increased consumption in period $t+2$, which allows for higher levels of utility.

The output produced domestically is purchased for three distinct purposes: for consumption, for domestic investment, and for international investment. So the opportunity cost of investing in any one of these cases is the lower level of utility due to foregone current consumption. An additional cost is the lower level of output (implying less available for consumption and hence a lower level of utility) due to installation costs. This explains the right side of all Euler equations about optimal investment decisions. As mentioned, the left side is the marginal benefit of investing in period $t$. The first term capturing the marginal benefit is due to the increased production opportunities available with higher future levels of capital stock. As the agent invests one unit in period $t$, the capital stock in period $t+1$ increases by one unit. This increased capital stock can be used for production in period $t+1$, which will provide cash that can be used to purchase consumption goods in period $t+2$. This is the reason for discounting the term by $\beta^{2}$. The utility provided by this extra consumption is what the consumer cares about.

If one were to make use of Equation 18, then the optimal investment decisions reflected in Equations 31 and 32 could be rewritten as follows:

$$
\begin{aligned}
& \beta^{2} E_{t}\left[U_{c x_{t+2}} \frac{P_{t+1}^{x}}{P_{t+2}^{x}} \frac{f_{z, t+1}^{x}}{\left(1+R_{t+1}\right)} \frac{1}{\mu_{t+2}^{*}} g_{K_{t+1}^{x}}\right]+\beta E_{t}\left\{U_{c_{x t+1}}\left[(1-\delta)+\phi\left(K_{t+2}^{x}-K_{t+1}^{x}\right)\right]\right\} \\
& \quad=U_{c_{x t}}\left[1+\phi\left(K_{t+1}^{x}-K_{t}^{x}\right)\right], \\
& \beta^{2} E_{t}\left[U_{c x_{t+2}} \frac{P_{t+1}^{x}}{P_{t+2}^{x}} \frac{f_{z, t+1}^{x}}{\left(1+R_{t+1}\right)} \frac{1}{\mu_{t+2}^{*}} g_{K_{t+1}^{z}}\right]+\beta E_{t}\left\{U_{c_{t+1}} \frac{f_{z, t+1}}{\left(1+R_{t+1}\right)}\left[(1-\delta)+\phi\left(K_{t+2}^{z}-K_{t+1}^{z}\right)\right]\right\} \\
& \quad=U_{c x_{t}} \frac{f_{z, t}}{\left(1+R_{t}\right)}\left[1+\phi\left(K_{t+1}^{z}-K_{t}^{z}\right)\right] .
\end{aligned}
$$

A reinterpretation of the optimal investment conditions in Equations 33 and 34 allows observing the time line of events and their effect on the investment decisions. The first term on the left side of both equations shows the increase in the utility for the consumer in two periods' time, which justifies the discounting of the net utility by $\beta^{2}$. The net utility increase is explained 
as follows. An increase in the domestically or foreign-financed foreign capital stock increases the production of the intermediate good by their respective marginal productivity, i.e., $g_{K_{i+1}^{x}}$ and $g_{K_{i+1}^{z}}$. The overall optimal decision of FDI includes within it the benefit and cost of producing one more unit of the intermediate input $Z$, in this case of VFDI. As such, an increase in the consumption of the intermediate input $Z$ has a cost of decreasing utility due to the lower amount of consumption of the final good $X$. However, it provides the benefit of allowing increased production of the final good and profits due to this final good production, which allows for increased consumption and utility in one period's time. This benefit, due to the oneperiod time lag, is discounted by the nominal interest rate during that period, explaining the term $f_{i, t+1} /\left(1+R_{t+1}\right)$ in both equations, where $i$ stands for domestically or foreign-financed FDI ( $X$ and $Z$, respectively). This increased possibility of profits due to increased production of the final good $X$ allows the consumer to consume higher levels of goods in period $t+2$, as reflected in the discounting.

The second term on the left side in both equations is due to the increased benefit from the undepreciated portion of the foreign capital. In the case of the domestically financed FDI, $K_{x}$, the undepreciated capital, allows for using that portion of resources to purchase consumption goods that provide additional utility. Because the financing is made in terms of the domestically produced good itself, the prices do not enter the decision process. While the same intuition applies to the foreign-financed FDI, $K_{z}$, a proxy for the terms-of-trade is found to affect the marginal benefit of the foreign-financed FDI. This is because the resources that are made available as a result (i.e., the need for purchasing less foreign-financed capital) are valued in terms of the foreign currency (by $P^{-*}$ ), while the purchasing of the final good is valued in the domestic currency (by $P^{r}$ ).

In summary, the nominal variables that seem to be affecting the investment decision of the MNE in the case of VFDI include domestic inflation and monetary growth process, foreign inflation and monetary growth process, and the relative prices that could possibly be interpreted as the terms-of-trade. I next look into the relationship between the monetary growth processes and the choices of domestic investment, domestically financed FDI, and foreign-financed FDI.

\section{Steady State}

To discuss the investment-smoothing behavior of the MNE, I next discuss the steady state condition. Under steady state, consumption and capital stocks are constant. The prices evolve according to the growth rate of money. Therefore, one could envisage prices as being exogenously determined by the monetary growth rate process. This is along the lines of many papers that use the CIA framework (see Stockman 1981, Cooley and Hansen 1989, and Banerji and Marjit 1992). ${ }^{15}$ I will be looking into the deterministic model, where the growth rate of money is known to the economic agents and there is no stochastic disturbance. This allows simplification of the Euler equations previously discussed and provides further insight into the investment-smoothing behavior of the MNE.

\footnotetext{
15 This allows me to pin down the shadow value of money in the model, the Lagrange multiplier, $\lambda$. Equation 12 therefore suggests that the growth rate of money, which pins down the inflation, in fact also pins down the growth rate of $\lambda$ in this framework.
} 
Using the steady state conditions, I rewrite the Euler equations regarding the investment behavior for domestic investment, domestically financed FDI, and foreign-financed FDI. For the domestic capital situation, I can rewrite Equation 30 as follows:

$$
\beta^{2}\left(\frac{1}{\mu} \frac{1}{\mu} f_{K}\right)+\beta(1-\delta)=1 .
$$

The domestically financed FDI's Euler Equation 33 is rewritten as follows:

$$
\beta^{2}\left[\frac{1}{\mu} \frac{f_{z}}{(1+R)} \frac{1}{\mu^{*}} g_{K^{x}}\right]+\beta(1-\delta)=1 .
$$

Finally, the foreign source-financed FDI's Euler equation can be further simplified as follows:

$$
\beta^{2}\left(\frac{1}{\mu} \frac{1}{\mu^{*}} g_{K^{*}}\right)+\beta(1-\delta)=1
$$

Each equation is suggestive of the domestic and foreign inflation tax on the MNE's investment decisions, both through higher monetary growth rates, $\mu$ and $\mu^{*}$, and the effects of inflation on the nominal interest rate, $R$.

The discussion of the investment-smoothing behavior of the MNE is most clearly observed using Equations 35, 36, and 37 in tandem:

$$
\left(\frac{1}{\mu} f_{K}\right)=\left(\frac{f_{z}}{(1+R)} \frac{1}{\mu^{*}} g_{K^{*}}\right)=\left(\frac{1}{\mu^{*}} g_{K^{z}}\right) .
$$

I start by discussing the effects of an increase in domestic inflation, depicted by the higher domestic monetary growth rate, $\mu$. The direct effect of higher domestic inflation is evident in the first part of the equality in Equation 38, where the net benefit of investing domestically decreases. To obtain equality across the three types of investments' net benefit, the MNE could be assumed to first respond by increasing the marginal productivity of the domestic capital to counteract the decrease in the net benefit due to the inflation tax. To discuss marginal productivity, I need to define the production function in more detail. In the following discussion, the most general form of production function is assumed for both $X$ and $Z$, assuming both to be constant elasticity of substitution (CES) production functions.

Using the CES production function, one can ensure diminishing marginal productivity as long as the factors are not perfectly substitutable. ${ }^{16}$ As such, for the following discussion I rule out perfect substitutability of domestic capital, $K$, and the foreign-produced intermediate input, $Z$. Returning to the discussion of the effects of an increase in the domestic inflation rate, one can then observe that the MNE reduces domestic investment activity to reduce the domestic capital stock and allow for increased marginal productivity of the capital to compensate for the inflation tax effects. However, in the following discussion, I show that the MNE could in fact opt to keep the domestic investment intact, increasing foreign investment to counteract the loss on account of domestic inflation. The extent of reduction in domestic investment and increase in foreign investment would depend on the preference of the firm across these two investment opportunities, which I do not explicitly model here. Regardless of such a preference being modeled, however, the model is able to strongly show that the existence of foreign investment

${ }^{16}$ This follows Robinson (1933). 
opportunities reduces the real effects of domestic inflation on domestic investment, where at the extreme the effects could be fully eliminated.

The fall in the domestic capital stock not only influences the marginal productivity of the domestic capital itself but also that of the intermediate input $Z$. In fact, the CES production function can be depicted as follows:

$$
X=\left[\alpha K^{\rho}+(1-\alpha) Z^{\rho}\right]^{1 / \rho},
$$

where $\rho$ captures the extent of substitutability between the two factors of production, $K$ and $Z$, ranging from 1 (perfect substitutes) to $-\infty$ (Leontief).

The CES production function implies that the marginal productivity of the intermediate input always increases with domestic capital stock. ${ }^{17}$ Therefore, the adjustment in the domestic capital stock due to the inflation tax also affects the middle portion of Equation 38, which captures the net benefit of the domestically financed FDI. This decrease in the marginal productivity of the intermediate good $Z$ is larger the more complementary are the domestic capital and the intermediate good. Alongside the indirect effect of the inflation tax in reducing the net benefit of domestically financed FDI, higher domestic monetary growth rates also induce higher nominal interest rates $(1+R)$, further reducing the net benefit for the domestically financed FDI. Therefore, the domestic inflation tax on FDI is evident in the decrease in the overall net benefit of domestically financed FDI, evident in the decrease in the ratio $f_{\beth} /(1+R)$.

When domestic capital and the imported intermediate input are substitutes, this decrease will be relatively small in magnitude, inducing a possible increase in the domestically financed FDI. One can see this in Equation 39: The increase in domestic inflation directly reduces the net benefit of domestic investment, while it directly and indirectly reduces the net benefit of domestically financed FDI. When $K$ and $Z$ are substitutes, the direct effect is much larger in magnitude than the indirect effect, causing the MNE to reduce domestic investment and smoothing the losses by shifting part of this investment to the host country in the form of domestically financed FDI. However, when $K$ and $Z$ 's complementarity increases, the indirect effect starts dominating. Indeed, the overall magnitude of decrease in the net benefit of FDI could be large enough, significantly causing both domestic investment and domestically financed FDI to decrease as a result of domestic inflation tax.

While these changes occur, the last part of Equation 38, depicting the net benefit of foreign-financed FDI, is only indirectly affected by the domestic inflation tax. To achieve equality of net marginal benefits across the three types of capital, the MNE increases foreign source-financed FDI under all cases of substitutability of $K$ and $Z$ to induce a decrease in the marginal productivity of $K_{z}$, the foreign source-financed FDI. ${ }^{18}$

In summary, an increase in the domestic inflation tax induces investment-smoothing behavior by the MNE. While the MNE definitely reduces domestic investment and increases foreign source-financed FDI, the effects of the domestic inflation tax on the domestically financed FDI depends on the substitutability between the domestic capital and the imported

\footnotetext{
${ }^{17}$ The CES allows showing that $f_{z} / \hat{c} K \geq 0$. The cross derivate is zero when the two factors are perfect substitutes, a case I rule out by assumption in this discussion.

${ }^{18}$ Because the domestically and foreign-financed FDI are perfect substitutes, a change in any one of these investment decisions has no cross effect on the marginal productivity of the other type of investment. This allows the discussion of investment smoothing between the two types of FDI to be restricted to domestically and foreign-financed FDIs.
} 
intermediate input. The less substitutable the two are (i.e., the more complementary), the higher the probability that the MNE also reduces the domestically financed FDI on account of the inflation tax. When such alternative means for investment were not available, in other words investment-smoothing behavior was not possible, the increased domestic inflation tax would decrease the domestic investment by a larger magnitude. However, when investment smoothing across countries and alternative means of financing are available, the net benefit adjustment not only occurs through domestic investment but also through FDI, somewhat limiting the negative effects of the domestic inflation tax on domestic investment. In the extreme case one could even envisage a case where the MNE chooses not to reduce domestic investment at all, countering the loss in net benefit of investment by fully adjusting FDI behavior.

The results emphasize that in an empirical testing of the effects of domestic inflation on FDI outflows, the sign of the coefficient depends on the substitutability of factors of production and the financing sources of FDI. ${ }^{19}$ As such, ambiguous findings of the empirical link between inflation and FDI could be due to the aggregation of the data that hides these two important dimensions of the investment. A proper estimation would require a more disaggregated data analysis of FDI that allows capturing the sources of finance for FDI activity and the characteristics of complementarity across domestic and foreign capital.

The discussion of an increase in the foreign inflation rate is symmetric across the two alternatively financed FDIs. The direct effects of an increase in the foreign inflation tax is to reduce the net benefit of the domestically and foreign source-financed FDI in equal amounts. ${ }^{20}$ To compensate for the decline in their net benefit, the MNE reduces both types of FDI. The investment-smoothing opportunity suggests that the MNE will instead invest in the domestic economy. Alongside this investment-smoothing effect on domestic capital, the decrease in overall FDI suggests a decrease in the amount of $Z$, which will increase the marginal productivity of $Z$, positively contributing to the net benefit of domestically financed FDI. This indirect effect becomes a compensating factor, suggesting that the decrease in the domestically financed FDI will be lower in magnitude than the decrease in the foreign source-financed FDI. As in the case of an increase in the domestic inflation rate, the investment-smoothing opportunity suggests that the real effects of the inflation tax will be less than in the case of no such opportunities.

To summarize, the analysis provides three important insights regarding the role of FDI. First and foremost, the model suggests that the opportunity for investment smoothing via FDI reduces the quantitative real effects of inflation tax. In other words, FDI (domestic investment) plays the role of a hedging instrument in the case of a negative domestic (foreign) change. Therefore, when there is no other means of hedging against risks, production shifting (FDI) or shifting across alternative sources of FDI financing becomes the preferred method. Second, the results point to the importance of discussing the substitutability of factors of production in studying the link between FDI and inflation rates. When the vertically integrated MNE's production of the intermediate input is a substitute for domestic capital, domestically financed FDI increases while domestic investment falls, and vice versa when they are complements. Finally, the effects of domestic and foreign inflation differ across the different source-financed FDI, pointing to the importance of identifying how the FDI is financed when discussing the pattern of FDI.

\footnotetext{
${ }^{19}$ In studying the growth effects of FDI, Alfaro et al. (2006) also emphasize the important role of taking complementarity into account across factors of production.

${ }^{20}$ This is based on the premise that the two are perfect substitutes and their marginal productivities are in fact the same.
} 


\section{Horizontal FDI}

Unlike VFDI, HFDI is based on the premise that trade costs are higher than those that generate VFDI, giving reason for MNEs to explore foreign markets through FDI rather than trade. ${ }^{21}$ In this case I need not make any assumption regarding the relative productivity of the two countries. In other words, the wages need not be different between the two countries. Instead of licensing its production technique, as discussed, I argue that intangible asset ownership by the MNE leads it to shift production of the final good to the foreign country instead. The reason for HFDI is high trade or transportation costs. Therefore, in this section I incorporate trade barriers into the model.

The MNE produces two final goods to serve two separate markets. Good $X$ is produced and consumed in the home country, while good $X^{*}$ is produced by the MNE in the foreign country and is only consumed in the foreign country. ${ }^{22}$ The production of $X$ requires domestic labor, $L^{d}$, and domestic capital, $K$. The production of $X^{*}$ requires foreign labor, $L^{d^{*}}$, and FDI, which is both domestically and foreign source-financed. The portion that is domestically financed is in terms of the domestically produced good $X$ and is denoted as $K^{x}$. The foreignfinanced portion is in terms of the foreign good $X^{*}$ and is denoted as $K^{x^{*}}$. These notations are similar to the VFDI case.

The main difference between the VFDI and HFDI cases is regarding the end use of the foreign country-based production, $X^{*}$. In the VFDI case the final good $Z$ is exported back to the home country of the MNE, while in the case of the HFDI the final good $X^{*}$ is consumed in the foreign country. As such, in the HFDI case the goods produced in two alternative locations can in fact be thought of as being the same good, their only difference being the location of consumption and production. ${ }^{23}$ Because I can think of these two goods as being the same, then I could write the law of one price as not holding due to the trade barrier. Because I will only have two goods, there will be no relative prices beyond that of the same good in two different countries. Therefore, the law of one price holds with deviation, where the distortion is due to trade costs, denoted by $\tau^{24}$ :

$$
e_{t} P_{t}^{r^{* *}}\left(1+\tau_{t}\right)=P_{t}^{r} \text {. }
$$

The utility function and the law of motions for the three respective capital stocks are similar to the respective functions in the VFDI case. The CIA constraint regarding the domestic money does not change; however, the CIA for the foreign currency is altered due to the change in the use of the foreign country-based produced good, $X^{*}$. The foreign currency CIA is as follows, where the foreign currency, $N$, is used to purchase only foreign-financed capital:

$$
N_{t} \geq P_{t}^{\gamma^{*}}\left[K_{t+1}^{x^{*}}-K_{t}^{x^{* *}}(1-\delta)\right]
$$

\footnotetext{
21 There are also models of HFDI that do not require high trade costs to explain FDI, but FDI is used by the multinationals as a way of diversifying production locations to reduce risk or to equate marginal costs across different production locations. In the current analysis, for simplicity, I will focus only on the role of trade costs.

22 Because the two goods are the same in the HFDI case, I drop the notation of $Z$, which is replaced by good $X^{*}$, where the asterisk reflects the foreign variables.

${ }^{23}$ Please see footnote 8 for a discussion on the limitations of this modeling of production and direct investment possibilities.

${ }^{24}$ Note that, in line with the HFDI literature. I am assuming that the home country is a capital exporter, implying that $\tau$ is positive. In cases where $\tau$ is between -1 and 0 the country would be a capital importer and domestically financed FDI would either be negative or zero. This case is not explored in the article.
} 
The overall budget constraint, which is normalized for stationarity, is as follows:

$$
\begin{aligned}
& \frac{b_{t-1}^{h}}{\mu_{t}}\left(1+R_{t-1}\right)+\frac{e_{t} b_{t-1}^{f}}{\mu_{t}^{*}}\left(1+R_{t-1}^{*}\right)+\left[\frac{P_{t-1}^{x}}{\mu_{t}} f\left(K_{t-1}, l_{t-1}^{d}\right)-\frac{w_{t-1}^{\prime} l_{t-1}^{d}}{\mu_{t}}\right]+\frac{w_{t-1}}{\mu_{t}} l_{t-1}^{s}, \\
& +e_{t-1}\left[\frac{P_{t-1}^{r^{*}}}{\mu_{t}^{*}} g\left(K_{t-1}^{x^{*}}, l_{t-1}^{d^{*}}, K_{t-1}^{x^{*}}\right)-\frac{w_{t-1}^{*}}{\mu_{t}^{*}} l_{t-1}^{d^{*}}\right]+T R_{t} \\
& \geq P_{t}^{x}\left[c_{t}^{x}+K_{t+1}-K_{t}(1-\delta)+K_{t+1}^{x}-K_{t}^{x}(1-\delta)\right]+P_{t}^{r^{*}} e_{t}\left[K_{t+1}^{x^{*}}-K_{t}^{x^{*}}(1-\delta)\right]+b_{t}^{h}+e_{t} b_{t}^{f},
\end{aligned}
$$

with the choice variables of $c_{t}^{x}, l_{t}^{d}, l_{t}^{s}, l_{t}^{d^{*}}, K_{t+1}, K_{t+1}^{x}, K_{t+1}^{x^{*}}, b_{t}^{h}$, and $b_{t}^{f}$.

Using the previous equation and the relative price condition from Equation 40, I can rewrite the budget constraint as follows:

$$
\begin{aligned}
& \frac{b_{t-1}^{h}}{\mu_{t}}\left(1+R_{t-1}\right)+\frac{e_{t} b_{t-1}^{f}}{\mu_{t}^{*}}\left(1+R_{t-1}^{*}\right)+\left[\frac{P_{t-1}^{r}}{\mu_{t}} f\left(K_{t-1}, l_{t-1}^{d}\right)-\frac{w_{t-1} l_{t-1}^{d}}{\mu_{t}}\right]+\frac{w_{t-1}}{\mu_{t}} l_{t-1}^{s} \\
& +\left[\frac{P_{t-1}^{r}\left(1+\tau_{t-1}\right)}{\mu_{t}^{*}} g\left(K_{t-1}^{x}, l_{t-1}^{d *}, K_{t-1}^{z}\right)-\frac{w_{t-1}^{*}}{\mu_{t}^{*}} l_{t-1}^{d *}\right]+T R_{t} \\
& \geq P_{t}^{x}\left[c_{t}^{x}+K_{t+1}-K_{t}(1-\delta)+K_{t+1}^{x}-K_{t}^{x}(1-\delta)\right] \\
& \quad+P_{t}^{r}\left(1-\tau_{t}\right)\left[K_{t+1}^{z}-K_{t}^{z}(1-\delta)\right]+b_{t}^{h}+e_{t} b_{t}^{f} .
\end{aligned}
$$

The FOCs mostly follow those in the VFDI case, except for the equation reflecting the optimal decision of how much $Z$ to use in the final production, Equation 18, which allowed for reinterpretation of the optimal investment decisions.

Here, given the focus of my analysis, I discuss the Euler equations depicting the investment decisions of the MNE. The optimal investment decision of the domestic investment, domestically financed FDI, and foreign source-financed FDI, are depicted as follows, respectively:

$$
\begin{aligned}
& \beta^{2} E_{t}\left[U_{c x_{t+2}} \frac{P_{t+1}^{x}}{P_{t+2}^{x}} \frac{1}{\mu_{t+2}} f_{K_{t+1}}\right]+\beta E_{t}\left[U_{c x_{t+1}}(1-\delta)\right]=U_{c x_{t}}, \\
& \beta^{2} E_{t}\left[U_{c x_{t+2}} \frac{P_{t+1}^{x}\left(1+\tau_{t+1}\right)}{P_{t+2}^{x}} \frac{1}{\mu_{t+2}^{*}} g_{K_{t+1}^{r}}\right]+\beta E_{t}\left[U_{c x_{t+1}}(1-\delta)\right]=U_{c_{N},}, \\
& \beta^{2} E_{t}\left[U_{c x_{t+2}} \frac{P_{t+1}^{r}\left(1+\tau_{t+1}\right)}{P_{t+2}^{r}} \frac{1}{\mu_{t+2}^{*}} g_{K_{t+1}^{z}}\right]+\beta E_{t}\left[U_{c x_{t+1}} \frac{P_{t+1}^{r}\left(1+\tau_{t+1}\right)}{P_{t+1}^{x}}(1-\delta)\right]=U_{c x_{t}} \frac{P_{t}^{Y}\left(1+\tau_{t}\right)}{P_{i}^{r}} .
\end{aligned}
$$

As in the case of VFDI the two issues of interest are how all three investment decisions are affected by the domestic monetary growth rate, $\mu$, and the foreign monetary growth rate, $\mu^{*}$.

\section{Steady State}

As was discussed for the VFDI case, in the steady state, consumption and capital stocks are constant. The prices evolve according to the growth rate of money. Therefore, one could envisage prices as being exogenously determined by the monetary growth rate process. I continue looking into the deterministic model, where the growth rate of money is known to the economic agents and there is no stochastic disturbance. This allows simplification of the Euler 
equations just presented and provides further insight into the investment-smoothing behavior of the MNE.

Using the steady state conditions, I rewrite the Euler equations regarding the investment behavior for domestic investment, domestically financed FDI, and foreign source-financed FDI. For the domestic capital I can rewrite Equation 42 as follows:

$$
\beta^{2}\left(\frac{1}{\mu} \frac{1}{\mu} f_{K}\right)+\beta(1-\delta)=1 .
$$

The domestic source-financed FDI's Euler Equation 43 is rewritten as follows:

$$
\beta^{2}\left[\frac{1}{\mu} \frac{1}{\mu^{*}}(1+\tau) g_{K^{*}}\right]+\beta(1-\delta)=1 .
$$

Finally, the foreign source-financed FDI's Euler equation becomes the following:

$$
\beta^{2}\left[\frac{1}{\mu} \frac{1}{\mu^{*}} g_{K^{* *}}(1+\tau)\right]+\beta(1-\delta)(1+\tau)=(1+\tau) .
$$

Each equation is suggestive of the domestic and foreign inflation tax on the MNE's investment decisions, both through higher monetary growth rates, $\mu$ and $\mu^{*}$. Using Equations 45, 46, and 47 one can identify the investment-smoothing behavior of the MNE as follows:

$$
\left(\frac{1}{\mu} f_{K}\right)=\left[\frac{1}{\mu^{*}}(1+\tau) g_{K^{*}}\right]=\left(\frac{1}{\mu^{*}} g_{K^{v^{*}}}\right) .
$$

An increase in domestic inflation rate, $\mu$, reduces the net benefit of domestic investment without directly affecting the net benefit of either domestically or foreign source-financed FDI. This is a major difference from the VFDI case where a direct domestic inflation tax on the domestically financed FDI exists as well.

The direct inflation tax on domestic investment reduces the net benefit, which induces an adjustment via domestic investment. Once again, this requires a discussion of the marginal productivity of capital. As in the previous discussion, I assume a CES production function and allow for a range of substitutability between factors of production, except perfect substitutability. Ruling out the perfect substitution case suggests diminishing marginal productivity across the board. Hence, the MNE reduces domestic investment to compensate for the loss in net benefit due to the domestic inflation tax. As previously discussed, this reduction in domestic investment is less in the case where there are no alternative investment means. This is due to the ability of the MNE to invest alternatively in a foreign country, both as domestically financed and foreign source-financed FDI. By shifting investment from the domestic to the foreign economy, the MNE allows for the net benefits of the three types of capital to be equalized. This investment-smoothing behavior of the MNE reduces the negative real effects of the domestic inflation tax. Furthermore, as in the VFDI case, the existence of such investment-smoothing opportunities via FDI provides an alternative means of hedging against negative economic outcomes, in this case inflation.

An increase in foreign inflation, captured through an increase in $\mu^{*}$, only has direct effects on both the domestically and foreign source-financed FDI. Both of the net benefits of these capitals decrease because of the foreign inflation tax. To compensate for the loss in the net benefit and achieve equality across the net marginal benefits of the three types of capital, the MNE reduces FDI and compensates for the loss by increases in the domestic investment. Because the domestically financed FDI and the foreign source-financed FDI are perfect 
substitutes, their marginal productivities are the same, suggesting that not only do both types of FDI respond to the foreign inflation tax in the same direction, they could possibly also respond in the same magnitude. ${ }^{25}$ This symmetric behavior across the two types of FDI points to another difference in the behavior of MNEs that carry out VFDI and HFDI. A comparison of the investment-smoothing behavior of MNEs that carry out VFDI and HFDI is provided in the following section.

\section{Comparison across VFDI and HFDI}

To observe the different investment-smoothing behavior between the VFDI and HFDI, we can compare Equations 38 and 48, respectively, which I restate here as follows:

$$
\begin{gathered}
\left(\frac{1}{\mu} f_{K}\right)=\left[\frac{f_{z}}{(1+R)} \frac{1}{\mu^{*}} g_{K^{*}}\right]=\left(\frac{1}{\mu^{*}} g_{K^{*}}\right) \\
\left(\frac{1}{\mu} f_{K}\right)=\left[\frac{1}{\mu^{*}}(1+\tau) g_{K^{*}}\right]=\left(\frac{1}{\mu^{*} g_{K^{*}}}\right) .
\end{gathered}
$$

The effects of domestic inflation not only differ quantitatively but also qualitatively in the cases of VFDI and HFDI. In the case of VFDI, an increase in domestic inflation affects not only the absolute net benefit of domestic investment through an increase in $\mu$ but also the net benefit of domestically financed foreign investment through an increase in the domestic nominal interest rate, $R$. On the contrary, in the case of HFDI an increase in domestic inflation only affects the net benefit of domestic investment. The qualitative and quantitative effects of domestic inflation on domestic investment, in the case of VFDI, depend on two factors: the substitutability between factors of production and the relative marginal productivities of the two investments.

Furthermore, the effects across the FDI that is financed from different sources are also asymmetric across VFDI and HFDI. Multinational enterprises that undertake HFDI change the domestically and foreign-financed FDI in the same direction; whereas, MNEs that undertake VFDI change the domestically and foreign-financed FDI possibly either in the same direction or in the opposite direction, depending on the substitutability of the factors of production. If the factors of production in the home country production are complements, then the MNE responds to an increase in domestic inflation by reducing domestically financed FDI and increasing foreign source-financed FDI. As such, one could also depict cases where an increase in domestic inflation causes investment smoothing in any direction, i.e., an increase or decrease in domestically financed FDI alongside an increase in foreign-financed FDI, when the MNE is doing VFDI. The effects of domestic inflation in the case of HFDI are much clearer. An increase in domestic inflation only directly affects the net benefit of domestic investment. The qualitative effect of an increase in the domestic inflation rate is very clear when the MNE decreases its domestic inflation and shifts investments to the foreign country (both in the form of domestically financed FDI as well as foreign-financed FDI).

\footnotetext{
${ }^{25}$ Assuming the initial levels of $K^{x}$ and $\mathrm{K}^{*^{*}}$ are equal and $\tau$ is zero, the effects of inflation on the magnitude of both FDI would be identical.
} 
In case of an increase in the foreign inflation tax, the direct effect on domestically and foreign source-financed FDI is the same across VFDI and HFDI. However, on account of additional indirect effects via the intermediate input's production in the VFDI case, the overall results differ. In short, one observes that the foreign inflation tax induced decrease in the domestically financed FDI will be lower in magnitude than the decrease in the foreign sourcefinanced FDI when the MNE undertakes VFDI. On the other hand, the domestically and foreign-financed FDIs respond with similar magnitudes to higher foreign inflation rates when the MNE undertakes HFDI. ${ }^{26}$

These findings have important empirical implications. The empirical link between aggregate FDI and inflation, in both the home and the host country, could well hide existing dissimilar relationships between different types of FDI (vertical or horizontal, and domestically or foreign source-financed) and inflation. Therefore, one can expect that using aggregate FDI data in studying the link between FDI and inflation would create biases in the estimates and a mix of results across different countries. This finding is parallel to the discussion by Russ (2007), who shows that allowing for heterogeneity of firms and endogeneity of the exchange rates can influence the relationship between uncertainty and FDI, explaining the lack of robust results in the literature regarding the sign and magnitude of the relationship between exchange rate uncertainty and FDI. Both this article and Russ's work suggest that allowing for a more disaggregated analysis of FDI, in the case of this article in terms of the motivation and financing of FDI, would improve the empirical FDI studies.

\section{Conclusions}

The dynamic modeling of the investment decisions of a multinational firm has allowed investigation of the reactions of the multinational firm to one-time changes in domestic and foreign inflation. Inflation erodes the purchasing power of individuals, creating distortions in the net returns of investment and labor. The distortions are introduced into the model using CIA constraints. Foregone consumption (utility) in period $t$ reflects the cost of investing that period. Whereas the benefit is reflected in increased consumption (utility) in period $t+1$ because of more undepreciated capital, and increased consumption (utility) in period $t+2$, due to more production in period $t+1$. The sales of goods produced in period $t+1$ provide cash to acquire final goods in period $t+2$. During this period inflation erodes the purchasing power of earnings before they are converted into consumption (utility); thus, the net benefit of investing falls as inflation rises. This mechanism captures the direct negative effect of foreign (domestic) inflation on foreign (domestic) investment.

Being a MNE provides the firm with a hedging instrument against inflationary processes in both the home and the host country. The model shows that the ability of diversifying investment decisions as well as financing decisions across countries in response to inflation fluctuations reduces the fluctuations in physical investment. The results further point to

\footnotetext{
${ }^{26}$ If one were to adjust the model to allow for the intermediate good produced in the host country to be used for both production and consumption purposes in the home country, the results echo those of the HFDI case. Overall the results suggest that the factors that govern the investment decision of an MNE carrying out somewhat of a combination of VFDI and HFDI in nature are those of the HFDI parts of the FDI. As such, the interpretation of the results would follow the discussion for the HFDI case.
} 
differential investment-smoothing behavior when the MNE undertakes vertical or horizontal FDI upon increased domestic or foreign inflation. Finally, the model allows me to study the composition change in the financing of the FDI within the investment-smoothing behavior of the MNE.

The important prediction of the model, which has empirical consequences, is that the real effects of nominal variables depends on the type of foreign investment (it being vertical or horizontal), the financing patterns of the foreign investment, and the substitutability between the factors of production. Furthermore, the results point to an important role played by FDI, where the existence of FDI reduces the extent of negative real effects of inflation. This finding provides further evidence on the possible positive benefits of allowing freer FDI flows and further capital account liberalization.

Significant differences in the investment-smoothing behavior of MNEs investing in the form of VFDI and HFDI are suggestive of the importance of improving data collection that allows for differentiating between VFDI and HFDI. ${ }^{27}$ Furthermore, the analysis also suggests that aggregate data of FDI, which does not differentiate between the financing of the FDI, also hides the possible differential factors that drive the investment.

While the previous discussion allows for a discussion of the investment-smoothing behavior of the MNE upon inflation, it does not allow for a discussion of the quantitative effects of the inflation on FDI. An extension of the model, where an objective function of the MNE with differential preferences across the three types of investment is modeled, will allow quantification of the effects of inflation on FDI and domestic investment. This remains as an issue for future research.

\section{References}

Aizenman, Joshua. 1992. Exchange rate flexibility, volatility, and domestic and foreign direct investment. IMF Staff Papers 39(4):890-922.

Aizenman, Joshua, and Nancy Marion. 2004. The merits of horizontal versus vertical FDI in the presence of uncertainty. Journal of International Economics 62(1):125-48.

Alfaro, Laura, Areendam Chanda, Sebnem Kalemli-Ozcan, and Selin Sayek. 2006. How does foreign direct investment promote economic growth? Exploring the effects of financial markets on linkages. NBER Working Paper No. 12522.

Aschauer, David, and Jeremy Greenwood. 1983. A further exploration in the theory of exchange rate determination. Journal of Political Economy 91:868-75.

Banerji, Samjay, and Sugata Marjit. 1992. Capital mobility and anticipated inflation with cash-in-advance constraints. Journal of Macroeconomics 14(1):143-54.

Blonigen, Bruce. 1997. Firm-specific assets and the link between exchange rates and foreign direct investment. American Economic Review 87:447-65.

Cooley, Thomas F., and Gary D. Hansen. 1989. The inflation tax in a real business cycle model. American Economic Review, 79:733-48.

Demir, Banu, and Selin Sayek. 2007. Sectoral location choice of MNEs. Unpublished paper, Bilkent University.

Devereux, Michael B., and Charles Engel. 1999. The optimal choice of exchange-rate regime: Price-setting rules and internationalized production. NBER Working Paper No. 6992.

Dunning, John. 1993. Multinational enterprises and the global economy. Wokingham, UK and Reading, MA: Addison Wesley.

Feenstra, Robert C. 1998. Integration of trade and disintegration of production in the global economy. Journal of Economic Perspectives 12(4):31-50.

\footnotetext{
${ }^{27}$ In a recent analysis of the geographic location of FDI, Demir and Sayek (2007) suggest a means of identifying the extent of horizontal versus VFDI across two-digit sectoral classifications.
} 
Feldstein, Martin. 1994. Taxes, leverage and the national return on outbound foreign direct investment. NBER Working Paper No. 4689.

Froot, Kenneth, and Jeremy Stein. 1991. Exchange rates and foreign direct investment: An imperfect capital market approach. Quarterly Journal of Economics 106:1191-1217.

Gokcekus, Omer, and Edward Tower. 1997. The effects of import quotas on national welfare: Comment. Southern Economic Journal 64(2):584 87.

Helpman, Elhanan. 1984. A simple theory of international trade with multinational corporations. Journal of Political Economy 92:451-71.

Hummels, David, Jun Ishii, and Kei-Mu Yi. 2001. The nature and growth of vertical specialization in world trade. Journal of International Economics 54(1):75-96.

Hymer, Stephen H. 1976. The international operation of national firms: A study of direct investment. M.A. thesis, MIT, Boston, MA.

Kimbrough, Kent. 1990. Optimal taxation and inflation in an open economy. Journal of Economic Dynamics and Control 15:179-96.

Kindleberger, Charles P. 1969. American business abroad. New Haven: Yale University Press.

Lehmann, Alexander, Selin Sayek, and Hyoung Goo Kang. 2004. Multinational affiliates and local financial markets. IMF Working Paper 04-107.

Lucas, Robert. 1982. Interest rate and currency prices in a two currency world. Journal of Monetary Economics 10:335-59.

Markusen, James R., and Anthony J. Venables. 1998. Multinational firms and the new trade theory. Journal of International Economics 46:183-203.

Markusen, James R., and Anthony J. Venables. 2000. The theory of endowment, intra-industry and multinational trade. Journal of International Economics 52:209-34.

Mendoza, Enrique. 1991. Real business cycles in a small open economy. American Economic Review 81:797-818.

Navaretti, Giorgio Barba, and Anthony J. Venables. 2004. Multinational firms in the world economy. Princeton, NJ: Princeton University Press.

Robinson, Joan V. 1933. The economics of imperfect competition. London: Macmillan, Second edition with a new preface, 1969.

Russ, Katheryn N. 2007. The endogeneity of the exchange rate as a determinant of FDI: A model of entry and multinational firms. Journal of International Economics 71(2):344-72.

Stockman, Alan. 1981. Anticipated inflation and the capital stock in a cash-in-advance economy. Journal of Monetary Economics 8:387-93.

Sung, Hongmo, and Harvey E. Lapan. 2000. Strategic foreign direct investment and exchange-rate uncertainty. International Economic Review 41:411-23.

Svensson, Lars. 1985. Money and asset prices in a cash-in-advance economy. Journal of Political Economy 92(5):918-44.

Vernon, Raymond. 1966. International investment and international trade in the product cycle. Quarterly Journal of Economics 82(2):190-207.

UNCTAD (United Nations Conference on Trade and Development). 2003. World investment report: FDI policies for development national and international perspectives. Geneva: United Nations.

World Bank. 2006. World Development Indicators. Washington DC: World Bank. 